\title{
0582 WEDNESDAY EVE FESTIVAL INJURIES
}

M Haddadi*, G Masoumi, M G Afshar Correspondence: Ministry of Health \&Medical Education, No 1, Modir alley, Monshi street, Africa Boulevard, Tehran 1968853113, Iran

\subsection{6/ip.2010.029215.582}

Introduction In our country there was an ancient Wednesday eve festival during the last Wednesday evening of each year which included creating small fire and jumping over it with making good health wishes. Unfortunately for using fire crackers nowadays the real feature of this night has become similar to a war scene.

Methods Data was collected during 21 April 2009 till 20 March 2009 and carried out from all over the country. It was assessed and analysed in the Violence and injury prevention department of the Ministry of health and medical education. Different types of injuries were classified and correlated with age, sex, education, out come, activity while injury occurred and place or field of occurrence.

Result Overall, 1817 cases were registered in 41 medical universities. The most common type of injury was first degree burning (25.2\%), followed by abrasion and corrosion (24.6\%), and second degree burning (13.3\%). The most common place for injuries was road, street and highways (80.2\%) followed by home and around it. Overall, the commonest age of injures was 15-19 (25.8\%) followed by 20-24 (20.5\%). Males were more likely to be injured than female (83.2 vs 16.8). Hands (43.3\%) were the most common injured site in the Wednesday eve festival followed by eyes (24.5\%). Unfortunately three dead and four disabilities were reported.

Conclusion Preventive interventions most focus on pupils as the most vulnerable group and the schools as the most accessible field in Iran. 